\title{
¿Debo aprender una nueva clasificación?
}

\author{
Dr. Ernesto Bersusky
}

Editor, Revista de la AAOT

Si existe alguna cualidad del Ser Humano que lo distingue de otras especies es la capacidad de conocer.

La definición usual de "conocimiento" es quizás la de Wikipedia: "Hechos o información adquiridos por el Ser humano a través de la experiencia o la educación, la comprensión teórica o práctica de un asunto referente a la realidad". ${ }^{*}$

Es el pecado original del Ser Humano. El árbol prohibido al que se refiere la Biblia es el Árbol del Conocimiento; el haberlo probado simboliza la curiosidad por la realidad circundante, su adquisición y la posterior condena.

Esto se da en numerosas culturas y cosmogonías. Prometeo roba el fuego sagrado de los dioses y es condenado a vivir encadenado a una roca del monte Cáucaso donde un águila le devora el hígado, pero, como era un inmortal, el hígado le crecía por las noches y, al otro día, el águila nuevamente volvía a su torturante festín.

El fuego sagrado de los dioses no era otra cosa que la simbolización del conocimiento. Como bien se describe, la apropiación del fuego fue una de las primeras manifestaciones de conocimiento del homo sapiens.

Pero ¿cómo hace el Ser Humano para conocer, para tomar la realidad como dato e incorporarla como "conocimiento"?

Muchos antropólogos y filólogos han tratado de dar respuestas que no van más allá de la teoría.**

En algo estamos todos de acuerdo: la totalidad e infinitud de la realidad es inabarcable por una sola persona.

Jorge Luis Borges creó un personaje con una capacidad extraordinaria de recordar, Funes el memorioso, el cual, entre otras cosas geniales, en medio de su aburrimiento, decidió ponerles nombres propios a los números.

El sistema decimal no es sino una prueba de que nuestra capacidad de conocer los números es absolutamente limitada a series de diez. Existen sociedades que tienen tres números solamente: "uno", "dos" y "muchos".

La totalidad del conocimiento posible es un hecho puramente social y, como tal, se tiene que adecuar a códigos comunes. Estos códigos comunes, tal como el sistema decimal, no son otra cosa que las clasificaciones.

Las clasificaciones son una lectura finita de una realidad infinita. Representan la necesidad de limitar la incapacidad del Ser Humano de comprender el infinito y deben cumplir ciertas condiciones:

1. Cubrir la totalidad de la realidad.

2. Ser fáciles.

3. Incluir un pequeño número de categorías.

4. Ser reproducibles intraobservador e interobservador.

5. Ser un lenguaje común para la comunicación y la discusión.

Debemos agrupar la realidad en clases comunes, pero esta capacidad de clasificar, al mismo tiempo, es una muestra de hasta donde ha llegado el conocimiento en el preciso momento en el que ha sido formulada.

Una vez que el conocimiento avanza, van apareciendo las excepciones a estas clasificaciones que, al tratar de explicarlas como tales, en epistemología, se han denominado hipótesis ad hoc.

Cuando estas hipótesis ad hoc son ya demasiadas, la clasificación acordada cae y es remplazada por otra que abarca un mayor número de especímenes o hechos o fenómenos.

Este momento coincide, en general, con un cambio trascendental en la tecnología o en la concepción teórica. De todas maneras, los cambios en la concepción teórica no son otra cosa que los intentos de explicar las excepciones o, lo que es lo mismo, poder explicar lo que hasta ese tiempo no se podía explicar.

El conocimiento científico es el conjunto de hechos verificables y sustentados en evidencia recogidos por las teorías científicas, así como el estudio de la adquisición y elaboración de nuevos conocimientos mediante el método científico. $^{2}$ 
Este Editorial no pretende desarrollar este tema, pero podemos acordar que la finalidad del conocimiento científico es la verdad, aun asumiendo que dicha verdad evoluciona y cambia.

Específicamente en la rama del conocimiento en la cual trabajamos nosotros, la Ortopedia y la Traumatología, vivimos intensamente la progresión del conocimiento, reflejada aunque parcialmente, en permanente formulación y caída de las clasificaciones.

Nuestra tarea como investigadores es frente al hecho excepcional, aquello que no se puede explicar racionalmente con los elementos que nos da el conocimiento hasta ese momento.

Enfrentados a nuestro problema debemos preguntarnos ¿Por qué? y tratar de analizar, dar una nueva explicación o simplemente buscar la posibilidad de la explicación.

Esto no sólo nos enriquece intelectualmente como investigadores ni incrementa nuestro currículum, sino que también enriquece nuestra propia práctica médica.

Nuestra práctica médica está fusionada con nuestra práctica científica. Nuestras decisiones están o debieran estar fundadas en el conocimiento científico del problema por resolver y, frente al hecho diferente, al preguntarnos sobre su causalidad, estamos generando conocimiento.

Tomando como ejemplo las fracturas de la columna vertebral, hemos visto que tal vez la primera clasificación fue enunciada por Watson-Jones, ${ }^{3}$ que era una clasificación puramente anatómica y carecía de utilidad para instalar un tratamiento, puesto que todas se trataban, en ese momento, de la misma manera (corsé o reposo). De hecho, pensaba que todas las fracturas de columna eran por flexión.

Holdsworth ${ }^{4}$ observó que no todas las fracturas de columna vertebral se reducían en hiperextensión, por lo cual concluyó en que habría otros mecanismos en la génesis de una fractura y fractura-luxación de la columna y describió una nueva clasificación, más biomecánica, y distinguía entre columna anterior y posterior. Esto fue, de por sí, un paso importante para el conocimiento.

Con la aparición de la tomografía axial computarizada, Francis Denis ${ }^{5}$ desarrolla el concepto de columna media y la idea de las fracturas por lesión de dicha estructura ("burst fracture") y su indicación quirúrgica.

A continuación, Magerl y cols., ${ }^{6}$ de la escuela AO, desarrollan una nueva clasificación de base biomecánica, donde incorporan el mecanismo traumático y el grado de lesión ósea y ligamentaria, de una forma racional.

En 2005, Vaccaro y cols. ${ }^{7}$ le suman el estado neurológico del paciente, que previamente no había sido tenido en cuenta para la clasificación.

Como podemos observar con este ejemplo, las clasificaciones expresan la propia dinámica del conocimiento y está en la propia naturaleza del conocimiento su superación y remplazo por otras.

Por lo expuesto, ante la aparición de una nueva clasificación, memorizarla y razonarla es aprender nuevos conceptos.

No es una moda. Es un incremento del conocimiento. Es un nuevo horizonte.

"He cambiado conscientemente el término original "persona" por "Ser Humano" por parecerme que es más abarcativo.

** Recomiendo al lector las publicaciones de Noam Chomsky y más específicamente: El conocimiento del lenguaje, su naturaleza, origen y uso. Madrid: Alianza; 1989.

\section{BIBLIOGRAFÍA}

1. https://es.wikipedia.org/wiki/conocimiento

2. https://es.wikipedia.org/wiki/conocimiento_científico

3. Watson-Jones R. The treatment of fractures and fracture dislocations of the spine. J Bone Joint Surg 1934;16(1): 16-30. https://journals.lww.com/jbjsjournal/Abstract/1934/16010/THE_TREATMENT_OF_FRACTURES_AND_ FRACTURE.2.aspx

4. Holdsworth FW. Fractures, dislocations and fracture-dislocations of the spine. J Bone Joint Surg Br 1963;45:6-20. https://online.boneandjoint.org.uk/doi/pdf/10.1302/0301-620X.45B1.6

5. Denis F. The three column spine and its significance in the classification of acute thoracolumbar spinal injuries. Spine 1983;8:817-31. https://doi.org/10.1097/00007632-198311000-00003

6. Magerl F, Aebi M, Gertzbein SD, Harms J, Nazarian S. A comprehensive classification of thoracic and lumbar injuries. Eur Spine J 1994;3:184-201. https://doi.org/0.1007/BF02221591

7. Vaccaro AR, Lehman RA Jr, Hulbert RJ, Anderson PA, Harris M, Hedlund R, et al. A new classification of thoracolumbar injuries: the importance of injury morphology, the integrity of the posterior ligamentous complex, and neurologic status. Spine 2005;30:2325-33. https://doi.org/10.1097/01.brs.0000182986.43345.cb 